\title{
Perceptions of Educators of Reading Literacy; A Case Study of the Intermediate Phase in South African Primary Schools
}

\author{
U. Naidoo, *N. Dorasamy, K. Reddy \\ Durban University of Technology, South Africa \\ *nirmala@dut.ac.za
}

\begin{abstract}
The achievement of worldwide participation in education is essentially determined by the quality of education available. How well learners are instructed and how much they learn determines how regularly learners attend schools. Sound education is further affected by the following factors: time spent learning by learners, assessment methods for monitoring learner progress, styles of teaching, education spending, the language of instruction, and classroom organisation strategies (EFA Global Monitoring Report, 2005). However, the development of learners' literacy in South Africa as a developing country is accentuated by several challenges. Many learners in South Africa have difficulty understanding the language in which they are taught which is English, as they are not taught in their mother tongue. However, the language of instruction is not solely responsible for the poor performance in international reading tests and schooling in general. Learners are also faced with socio-economic issues, very little or hardly any parental supervision and educators are faced with the challenge of finding reading methods and strategies suitable to improving reading. Learners in the foundation phase are explicitly taught reading skills. In the intermediate phase, learners are expected to apply the skills acquired in the foundation phase to access the curriculum. In reality, this is difficult to achieve. The purpose of this article is to determine educator perceptions of reading literacy in the intermediate phase with the aim of enhancing reading literacy in the intermediate phase.
\end{abstract}

Key words: perception, literacy, intermediate phase, reading, educators, quality

\section{Introduction}

Education makes a significant contribution in assisting learners with the accomplishment of their own economic, social and cultural initiatives. Learners procure the skills, knowledge, values and attitudes for being accountable, involved and productive citizens by developing creatively and emotionally, in schools that focus on quality (EFA Global Monitoring Report, 2005). Educators need to determine the reading level of learners. There are many varieties of assessments employed in today's classrooms. Learners are given quizzes, pre-tests, and tests; these could be multiple choice, fill-in the blank, and/or essay. Educators present these assessments to determine whether learners have mastered the content being taught. Those who teach reading are no different. Since one of the main goals for the teaching of reading is for learners to comprehend what they are reading, educators of reading have to discover a way to measure whether their learners actually comprehended what was read. Many strategies are used to teach and assess reading performance. However, South Africa's democratic government inherited a divided and unequal system of education. Under apartheid, South Africa had nineteen different educational departments disconnected by race, geography and ideology. This educational system developed learners' readiness in different ways, for the positions they were expected to engage in, for example in social, economic and political life under apartheid. South Africa has 6 million adults over the age of 16 who have never attended school and cannot read or write and, therefore, cannot contribute effectively to the economy (Centre for Evaluation and Assessment, University of Pretoria, 2006). South Africa has been undergoing many changes in education, for example, a new curriculum with the introduction of the outcomes based education and the introduction of a single Department of Education, which replaced 19 different education departments of the past era. The rationalization of the civil service caused thousands of experienced, skilled and valuable educators to be removed from the education system, which had ultimately affected the quality of education in South Africa (Centre for Evaluation and Assessment, University of Pretoria, 2006).

South African Perspective: In facilitating an educational system that supports effective and efficient teaching and learning, the Department of Education National Curriculum Statement (NCS) (2002) refers to a 'balanced approach' to literacy development as its starts with learners' emergent literacy, subsequently connecting learners in reading 'real books', and writing for authentic reasons with a focus 
on phonics. An equal opportunity to all learners irrespective of race, religion or creed, to develop holistically through education in South Africa, has become the focus. The political history of South Africa has affected the quality of literacy and education in general in the country. Outcomes-Based Education (OBE) has played an essential role in dominating recent teaching methodology. The NCS (2002) policy document describes six learning outcomes for the language learning area. While these are offered as separate outcomes, they are expected to be incorporated into teaching and learning. The National Reading Strategy (DoE, 2008) affirms that learners should be acquainted with a variety of techniques to facilitate appropriate reading levels with comprehension; to extract information; and for pleasure. The South African education system has the challenge of providing quality education to a multicultural learner population in which there are 11 different official languages. English as a first language is spoken by less than $10 \%$ of the population (Howie, Venter and van Staden, 2008) and is one of the languages most frequently used by schools (the other being Afrikaans). As English is not the most frequently spoken language at home, the acquisition, mastery and learning of a second language is a reality for the majority of learners in South Africa. According to Howie et al., (2008), this language system is one of immersion, where a language that is not the language of the larger society, is used as a medium of instruction. The South African situation is complex. The National Department of Education's language policy stipulates that South African learners should receive instruction at school from grades 1 to 3 in their home language. However, in grade 4, learners are instructed in a second language, either English or Afrikaans. White, Indian and Coloured learners continue to receive instruction in the same language of instruction from grades 1 to 12, namely English or Afrikaans. However, African learners whose home language is not English or Afrikaans, receive instruction from grade 4 onwards in English or Afrikaans. This is despite current government language policy, which advocates that learning should take place in their home language from grades 1 to 12 (Howie et al., 2008). According to Rose (2006b), the history of schooling in South Africa complete with classroom methods and systems that have developed in western education, benefit the selected upper class and marginalise the majority. The Department of Education (DoE) of South Africa conducted a study in 2003 to determine the literacy levels amongst grade 3 learners. The results indicated that $61 \%$ of learners cannot read and write at their appropriate age levels and that up to $18.5 \%$ of learners in some provinces had to repeat grade three after being unable to satisfy the requirements of promotion to the next grade (Alliance for Excellent Education, University of Pretoria,2006:8). Therefore, it is necessary to determine educator perceptions of reading literacy in the intermediate phase.

Progress in International Reading Literacy: The Progress in International Reading Literacy Study (PIRLS) 2006 is an assessment of the reading comprehension of learners in the intermediate phase (grades 4 and 5). In 2006, PIRLS was administered to learners in the United States as well as 44 other jurisdictions around the world. The PIRLS assessment framework developed by the International Study Centre (ISC) in the U.S. was used to measure learners' performance on a combined reading literacy scale and on a literary sub-scale and an informational sub-scale. The literary sub-scale assessed performance in reading for literary experience, and the informational sub-scale in acquiring and using information. All participating jurisdictions used the same text, which was translated into the primary language or languages of instruction in that jurisdiction. PIRLS derives nationwide empirical data that is valuable to inform decisions on curriculum and language policy (PIRLS, 2006: iii). Data is derived from questionnaires, which are administered to all stakeholders including parents, educators, heads of institutions and learners. PIRLS is administered every 5 years, first in 2001 and then in 2006. Quality control monitors trained by the International Association for Evaluation of Educational Achievement (IAEEA), visited schools in each jurisdiction to ensure that the procedures specified by the IEA were implemented properly (U.S. Department of Education (U.S. DoE, 2007). PIRLS assists participating jurisdictions to understand the literacy skills of their learners within an international context. A comparative study reveals areas of strength, as well areas in need of improvement (U.S. DoE, 2007). Results of the above-mentioned international reading test indicate that South Africa is in urgent need of reading programmes that will encourage and maintain appropriate literacy levels nationally, as well as internationally. Reading is a component of nation building. The need to improve reading is essential to encourage and promote the confidence of learners in modern society and the wider world. Reading prepares learners to attain new information and knowledge that supports lifelong learning. Through reading, learners are enabled to be creative and engage critically in a world, which is constantly fluctuating and ambitious in nature (DoE, National Reading Strategy (NRS), 2008). South Africa has embarked on a National Reading Strategy, which is focussed on improving the reading competency of all learners, including those learners who encounter barriers to learning (NRS) (DoE, NRS, 2008). The NRS 
(DoE, 2008) aims to improve the reading and writing of learners so that they progress from grade to grade in the education system and contribute productively to the economy of South Africa.

\section{Initiatives to Improve Reading Literacy}

Annual National Assessments (Ana): Establishing a first-rate system of standardised national assessment is the priority of the Department of Education. This system fundamentally engages all learners in key grades (Grades 1 to 6) and learning areas to write standardised tests, which are similar across provinces and schools (DoE, ANA, 2011). ANA is a strategy of the Department of Basic Education (DBE) to develop the quality of learning outcomes in the education system. The results of ANA is a mechanism used as a critique of how the various strategies and interventions that the DBE applies impacts on the critical aspect of education, especially learner achievement (DoE, ANA, 2011). The intention of ANA is to examine learner performance each year in literacy and numeracy with the purpose of improving learner performance, aligned with pledges made by government. The ANA results scrutinize progress, guide planning and the allocation of resources to facilitate improvement in Literacy/Language and Numeracy/Mathematics knowledge and skills of learners in the grades concerned (Meier, 2011). The results are utilized for meaningful interventions to improve teaching and learning; especially in areas of specific knowledge and skills that learners were not competent in the ANA tests (DoE, ANA, 2011).

Foundations for learning campaign: The Education Department of South Africa envisages that every learner in South Africa should develop a solid foundation for further learning. With this aim in mind and in order to concentrate explicitly on improving the quality in literacy and numeracy, the Minister of Education in South Africa declared that the national Department of Education would set in motion the "Foundations for Learning" (FFL) campaign in South African schools in the Government Gazette of 14 March 2008 (No. 30880) (DoE, 2008). The FFL is a four-year campaign to generate a national focus on enhancing learner achievement in reading, writing and numeracy with the vision that by 2011 every learner should demonstrate age-appropriate levels of Literacy and Numeracy. This will be determined by a national evaluation at the end of 2011. The campaign is managed and controlled by a National Steering Committee (NSC) composed of leading educationalists from universities, research institutions and NGO's (Non-Governmental Organization) with proficiency and experience in literacy (DoE Foundations for Learning, 2008). The Foundations for Learning Assessment Framework is a document, which contains the 'milestones' for learners in the foundation and intermediate phase. The 'milestones' document indicates the expected level of achievement of learners in reading and writing for each term in the intermediate phase.

Scaffolding: A technique used to improve the quality of reading and writing in the intermediate phase in South Africa is 'scaffolding' (DoE Foundations for Learning, 2008). In scaffolding, the educators' support is necessary to encourage the development of skills in learners. When a task is demanding or arduous, the learner may require the complete support and encouragement of the educator. Once the learner progresses and gains skills and knowledge to become independent, the scaffolding (by the educator) is removed (DoE Foundations for Learning, 2008). "Learning to Read Reading to Learn" (LRRL) is a literacy instruction course intended to assist all learners to read and write at levels suitable to their age, grade and area of study. It has been developed with educators of primary, secondary and tertiary learners across Australia and internationally, to sustain reading and writing across the syllabus (Rose, 2006a:3). The instruction strategies of the course have been proven to allow weak readers to speedily learn to read and write at grade-appropriate levels, and superior learners to develop language understandings, further than their self-regulating competence. This method is termed 'scaffolding' (Rose, 2006a). Learners draw on values of scaffold learning, purposeful linguistics and genre approaches to writing in a structure that is easily reached, practical and meets the needs of educators and learners. There is considerable focus on improving literacy with substantial emphasis on improving reading and writing in the intermediate phase. Despite initiatives by the DBE, reading literacy in the intermediate phase still remains a challenge.

Literacy learning programme: Reading is a primary mode of learning in formal education and should be a central focus of classroom teaching. As reading becomes more and more important for learning, it becomes less and less a part of teaching. Most educators have received no previous training in teaching reading. Learners who are well prepared by their homes speedily learn to be independent readers in the early years, and are thus well prepared to start learning from reading in the upper primary years, while learners without this stage of home grounding are less well organized for upper primary, and may be 
harshly disadvantaged (Rose, 2006a). The following reading development curriculum illustrates how learners are prepared for each stage based on prior learning of the previous stage. Learners are taught reading skills in the junior primary phase. In the intermediate, senior and tertiary phase, learners are not explicitly taught reading skills but acquire them tacitly (Rose, 2006a). This series of instruction forward and assessment back is illustrated in Figure 1.

Figure 1: Reading development sequence in schooling (Rose, 2006a)

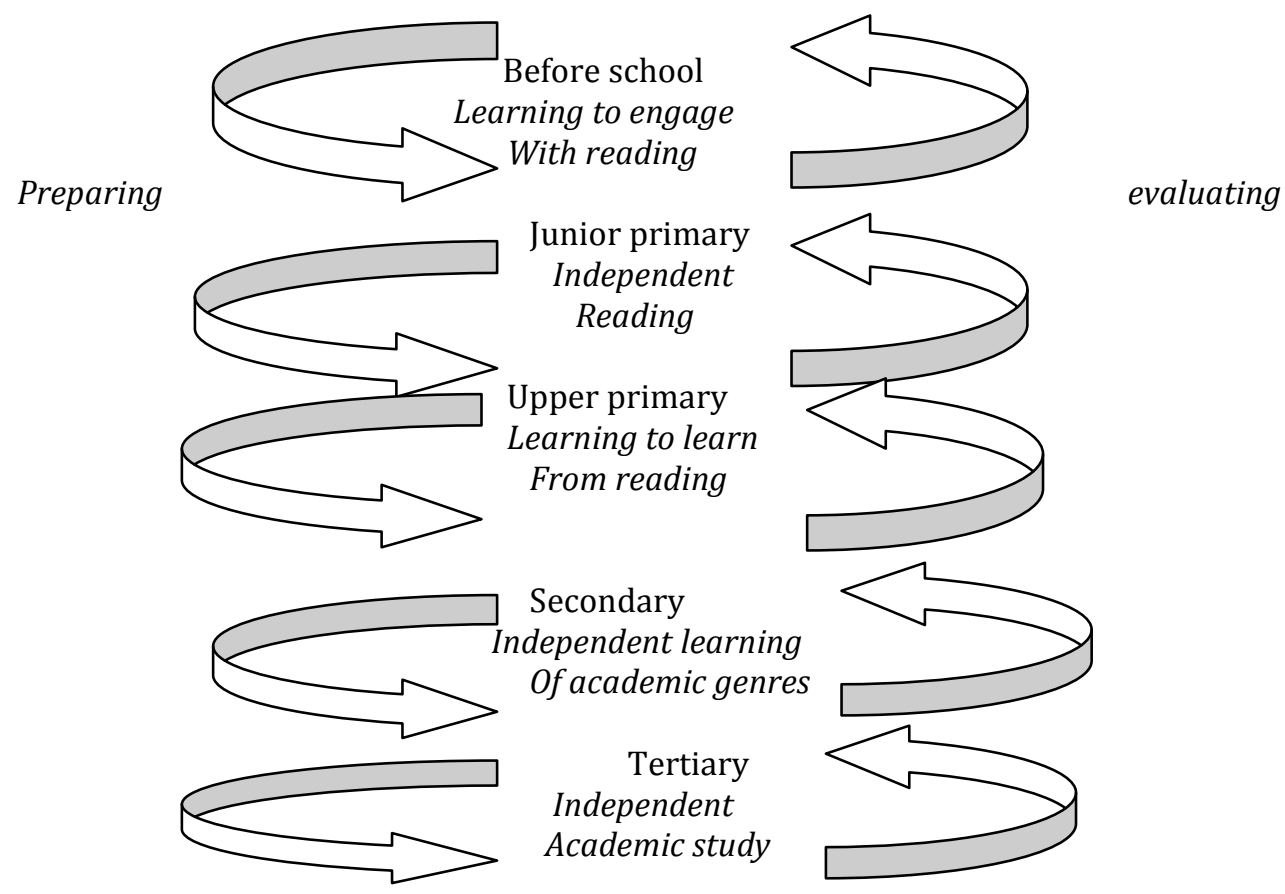

In South Africa, language learning is organized according to the Foundation Phase programme called the Literacy Learning Programme (LLP). The main focus is to give learners the foundations of reading, writing and basic literacy. In the intermediate phase, the programme is called the Languages Learning Programme (LLP). The main focus here is to develop the basic literacy that learners acquired in the earlier phase together with their thinking skills (DoE, 2007). The time allocation in the LLP for reading and writing literacy, for grade R, 1 and 2 is 9 hours 10 minutes per week. For grade 3 , the time allocation is 10 hours and the LLP for grades 4 to 6, is 7 hours and 30 minutes. Many schools teach English as the home language and Afrikaans as the first additional language. IsiZulu is taught as the second additional language. Ultimately, the language hours for grades 4 to 6 is shared between English, Afrikaans and IsiZulu. The time allocated for English is usually 5 hours in schools, which is insufficient to successfully teach the Learning Outcomes that underpin reading and writing (DoE, 2011). In November 2009, The National Department of Basic Education of South Africa emerged which, in collaboration with all major stakeholders in education, mounted a major mobilization programme to ensure that all schools become centres of excellence. The programme is known as the Quality Learning and Teaching Campaign (QLTC) (DoE, 2009). The Minister of Education, Naledi Pandor, launched the Foundations for learning document (which is a four-year campaign) in 2008, to improve the performance of learners in reading and writing in all South African schools. This campaign seeks to ensure that the average reading abilities of learners in grades 1 to grade 6 is increased by no less than $50 \%$ by 2011 (Mkhwanazi, 2008). The critical and developmental outcomes motivated by the Constitution, is the core foundation on which the Revised National Curriculum Statement (DoE, 2002) builds its Learning Outcomes. There are 6 main learning outcomes. Learning Outcome 3, which is Reading and Viewing, indicates that the learner will be able to read and view for information and enjoyment, and respond critically to the aesthetic, cultural and emotional values in texts. Learning Outcome 4, which is "Writing", indicates that the learners will be able to write different kinds of factual and imaginative texts for a wide range of purposes (DoE, RNCS, 2002). OBE's assessment framework defines specific language milestones for the intermediate phase (DoE, FFL, 2008). A National Framework for quality education in rural areas was devised and is the focal point for improving the quality of teaching and learning in rural and farm schools (SACMEQ, 2011). A further initiative of the Department of Education in South Africa to improve reading in schools is the National 
Reading Strategy, which focuses on providing professional support to educators and making reading resources accessible to learners (SACMEQ, 2011).

Reading programs: Prior to implementing the quality principles applicable to reading, it is important to investigate reasons for the need to improve the reading competency of learners. The analysis that is pursued in the following discussion relates to the reasons to improve reading. According to the South African Department of Education (2008), every educator in the intermediate phase is envisaged to devote at least 30 minutes daily to reading for enjoyment and at least 1 hour to extended writing every week. Educators are presumed to have adequate resources to warrant the effective teaching of reading and writing. This includes wall charts, writing materials, reading series, workbooks and writing materials (DoE, 2008). In South Africa, the formal teaching allocations for Literacy (Languages) in Grades 4, 5 and 6 are 7 hours and 30 minutes. The Literacy Focus Time ( 60 minutes) in the intermediate phase is 3 times per week in the Language of Learning and Teaching (LOLT) or Home Language (HL) and 2 times per week in First Additional Language (FAL) or HL. In the Language development (30 min), learners do Writing and Listening and Speaking in the LOLT each once a week and in the FAL each once a week. The Second Additional Language (SAL) can be introduced in the fifth weekly time-slot (DoE, FFL, 2008). In the intermediate phase (grades 4, 5 and 6), learners extend their literacy skills and raise their confidence and fluency in using oral language. Cross-curricular work forms an integral part of learning activities. Learners are introduced to oral and written literature and to important social and environmental issues by using texts that are longer and more intricate (RNCS, 2002). It is anticipated that every school should assess, monitor and capture the learners' progress and achievement in the key areas of reading and writing. Learners are to be subjected to annual national assessments in literacy, using standardized tests to measure progress regarding the achievement of set objectives (DoE. 2008). The primary goal of a reading programme should be to assist learners to acquire the skills and confidence to become successful independent readers. Readers benefit from observing the aspects a more proficient reader demonstrates and requires guidance in practicing and applying strategies independently without support (DoE, 2008). According to the FFL (2008), "read aloud", "shared reading" and "guided reading" by the educator and learner form the components of a reading programme. The "guided reading" constitutes a significant segment of the reading process. In the intermediate phase, during "guided reading", learners of similar reading requirements are grouped and instructed under the guidance of an educator.

The educator selects the text that is at the learners' instructional reading level and will reinforce or introduce appropriate reading strategies and concepts. The format of the lesson is dependent on the stage of reading development of the learners. As the fluency of learners increases, the lesson format and preparation increases to varying degrees of intensity. During the guided reading lesson, the educator assists learners in employing different cueing methods that will support them as they read (FFL, 2008). According to Pretorius (2005:799), most school systems generally provide explicit teaching of reading in the foundation phase, by the end of which learners are expected to be independent readers. Learners in the intermediate phase whose reading and writing skills in the foundation phase were not mastered, experience barriers to reading and writing. As maintained by Rose (2005), the problem is further compounded as many educators in the intermediate phase lack the skills and knowledge of teaching reading (phonics, decoding and syllabification: methods which foundation phase educators are usually familiar with in their teaching training). Moore and Hart (2007) believe that many learners in the first three years of schooling focus on decoding skills at the expense of comprehension. The result is that many learners resort to 'barking at the print', reading with accurate pronunciation, but with little understanding of what they read. The "Learning to Read: Reading to Learn" approach by Rose (2005) does not depend on the ability of the learner to name or sound out letters of the alphabet. It emphasises "meaning in context" as the starting point for teaching reading in manageable tasks. This method focuses on repeated practise until every learner can read and write sentences and then paragraphs.

\section{Methodology}

Literature Study: A literature study was undertaken with a view to assembling and integrating material relating to reading literacy in the intermediate phase of schooling. Initiatives to improve reading literacy were investigated. Further, factors in the education system that contributes to poor reading and writing abilities of learners and strategies to improve the quality of reading, were examined. This study is significant as it aims to bridge the gaps identified in the literature study and to present consequential guidelines to identify problems and create a more apparent understanding of the contemporary operations regarding the quality of reading in the intermediate phase at schools. 
Empirical Research: The ultimate goal relating to educational research, according to Ary, Jacobs and Sorensen (2010) is to ascertain general principles or explanation of behaviour that individuals can use to explain, predict, and control events in educational situations to create scientific theory. Research design constitutes a logical flow of activities to acquire research participants, to accumulate information from them and to formulate conclusions about a research problem. The design for this study entails a combination of qualitative and quantitative methods. A questionnaire was designed to collate information on factors affecting reading literacy, language and reading instruction, strategies for teaching reading, resources available for reading, systems for improving quality reading and reading as a homework activity. The questionnaire was the most appropriate instrument of data collection as it enabled educators to present reading related issues in writing. The information acquired revealed the status of the intermediate phase reading in South Africa. The literature review investigated organizations and management systems responsible for quality education. Factors that affect reading literacy were established and strategies to facilitate improvement in reading literacy were examined. The study employed the survey method as an instrument for data collection. The survey entailed the use of a questionnaire to collect facts, opinions and attitudes. This is indicated in the flow diagram in figure 2.

Figure 2: Flow diagram for design of research

Review of literature<smiles>[CH]=C</smiles>

Questionnaire/Survey<smiles>[CH]=C</smiles>

Questionnaire administration

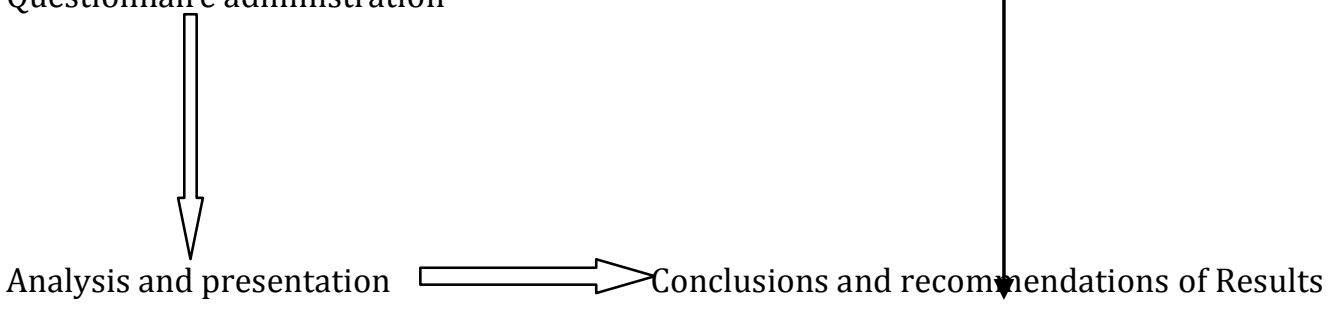

The questionnaire was personally delivered and collected from schools. The questionnaire was administered to managers and educators of primary schools in the North Durban region of KwaZulu Natal. The data was collected over a three-week period. Questionnaires were distributed to 450 people and a response rate of $81 \%$ was achieved. The total number of questionnaires collected was 366 and there were no inaccuracies. The questionnaires were self-explanatory.

Study population: The recent restructuring of the Education Department effected the merging of the former circuits into clusters. The cluster geographically extends from Umlazi in the south to Umhlanga in the north and from the Bluff in the east to KwaSanti (Pinetown) in the west. All schools in the cluster represent both public state schools and independent schools. These schools are serviced by ward managers. The cluster is divided into 8 wards and each of the wards is managed by a ward manager who is the Superintendent of Education (management). Each ward comprises of about 40 schools. The target respondents for this study were educators and management in the Umgeni north region, which represents one of the 8 wards in KwaZulu Natal. Random sampling was used and 40 schools participated. A sample of 450 educators was selected. The questionnaire was completed by 366 respondents. A fair sample of educators from schools representing different race groups (Coloured, Indian Blacks and Whites) was selected to ensure an unbiased participation.

Cronbach's Alpha (SPSS ver. 17.0 from the help menu): Reliability refers to the property of a measurement instrument that causes it to give similar results for similar inputs. Cronbach's alpha is a measure of reliability. More specifically, alpha is a lower boundary limit for the true reliability of the survey. Mathematically, reliability is defined as the proportion of the variability in the responses to the survey that is the result of differences in the respondents. That is, answers to a reliable survey will differ 
because respondents have different opinions, not because the survey is confusing or has multiple interpretations. The computation of Cronbach's alpha is based on the number of items on the survey (k) and the ratio of the average inter-item covariance to the average item variance.

$$
\alpha=\frac{\mathrm{k}(\mathrm{cov} / \mathrm{var})}{1+(\mathrm{k}-1)(\operatorname{cov} / \mathrm{var})}
$$

Under the assumption that the item variances are all equal, this ratio simplifies to the average inter-item correlation, and the result is known as the Standardized item alpha (or Spearman-Brown stepped-up reliability coefficient).

$$
\alpha=\frac{\mathrm{kr}}{1+(\mathrm{k}-1) \mathrm{r}}
$$

Notice that the Standardized item alpha is computed only if inter-item statistics are specified. In addition, remember, the coefficient of 0.921 reported for these items is an estimate of the true alpha, which in turn is a lower boundary limit for the true reliability.

Cronbach's Alpha (Introduction to SAS.UCLA): Cronbach's alpha measures how well a set of items (or variables) measures a single unidimensional latent construct. When data have a multidimensional structure, Cronbach's alpha will usually be low. Technically speaking, Cronbach's alpha is not a statistical test - it is a coefficient of reliability (or consistency). Cronbach's alpha can be written as a function of the number of test items and the average inter-correlation among the items. Below, for conceptual purposes, we show the formula for the standardized Cronbach's alpha:

$$
\alpha=\frac{N \cdot \bar{c}}{\bar{v}+(N-1) \cdot \bar{c}}
$$

Here $\mathrm{N}$ is equal to the number of items, c-bar is the average inter-item covariance among the items and vbar equals the average variance.

One can see from this formula that if you increase the number of items, you increase Cronbach's alpha. Additionally, if the average inter-item correlation is low, alpha will be low. As the average inter-item correlation increases, Cronbach's alpha increases as well. This makes sense intuitively - if the inter-item correlations are high, and then there is evidence that the items are measuring the same underlying construct. This is really, what is meant when someone says they have "high" or "good" reliability. They are referring to how well their items measure a single uni-dimensional latent construct. Thus, if you have multi-dimensional data, Cronbach's alpha will generally be low for all items. In this case, run a factor analysis to see which items load highest on which dimensions, and then take the alpha of each subset of items separately.

Reliability: Reliability is computed by taking several measurements on the same subjects. A reliability coefficient of 0.70 or higher is considered as "acceptable". The results are presented below. Section A represented the Demographic Data.

\begin{tabular}{ll}
\hline Section & Cronbach's Alpha \\
\hline B. Questions 9-17 & .671 \\
C. Questions 18-19 & .803 \\
D. Questions 20-25 & .831 \\
E. Questions 26-32 & .875 \\
F. Questions 33-37 & .769 \\
G. Questions 38-42 & .854 \\
Overall & .906 \\
\hline
\end{tabular}

The overall reliability score of 0.906 indicates a high degree of acceptable, consistent scoring for the different categories for this research. All of the categories have (high), acceptable reliability values.

Study Limitations: The study was reserved to intermediate educators only. The grade 7 educators that teach reading at a primary school were excluded. Other areas of Kwa-Zulu Natal were excluded from the study. 


\section{Results and Discussion}

Reading is a source of knowledge and its importance has increased. There is a need for all educators to make a conscious effort to improve reading literacy in schools. It is imperative that educators engage the minds of learners through proper reading strategies that improve reading literacy. According to the findings from the empirical study, there were a significant number of educators that received no training in teaching reading and a majority of the respondents indicated that they did not regularly attend workshops in teaching reading. According to Rose (2006), most educators have received no previous training in teaching reading. These impacts on the improvement and quality of reading literacy. Figure 3 below indicates the number of educators that attended workshops.

Figure 3: Attendance at workshops on reading strategies

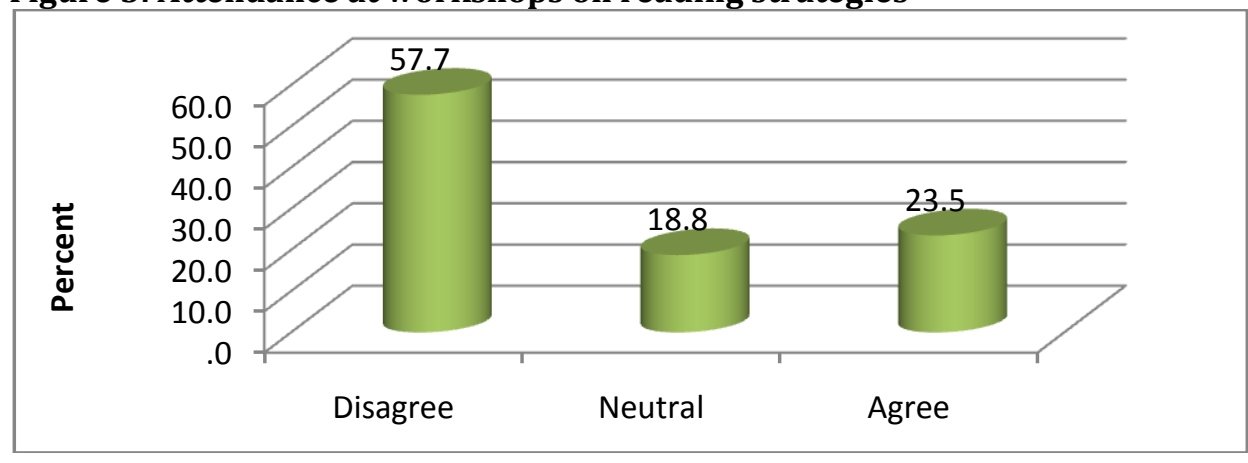

Approximately 58\% of the respondents indicated that they did not attend workshops regularly. Nearly a quarter $(23.5 \%)$ indicated that they did attend frequently.18.8\% of the respondents remained neutral about attending workshops on reading strategies. The responses indicate that the majority of educators are not work shopped regularly. According to the National Reading Strategy (Doe, 2008), numerous educators in South Africa have an inadequate perception of teaching literacy, reading and writing. Educators are not familiar with a method of teaching reading, which may be suitable to the learning approach of all learners. The National Reading Strategy (Doe, 2008) emphasises that educators are not acquainted with how to motivate reading inside and outside the classroom. This is a major challenge facing schools as it impacts on the quality of teaching of reading.

Number of learners: The number of learners that are, on average, in the respondents' classes is shown in Figure 4 below.

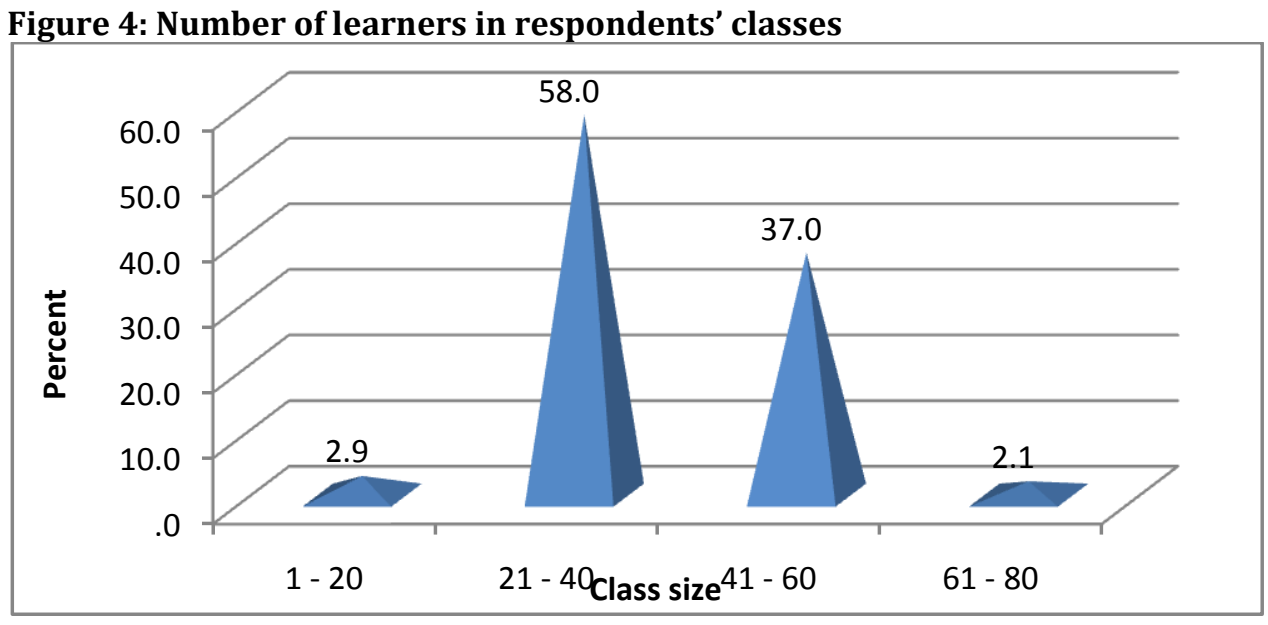

Most respondents have between 21 - 40 learners (58.0\%) and a significant proportion (37\%) have between $41-60$ learners. 2.9\% have between 1-20 learners, whilst, $2.1 \%$ have between 61 and 80 learners in their class. According to (SACMEQ, 2011), the educator-learner ratio and class size impacts on teaching and learning. The recommended educator-learner ratio and class size in South African primary schools is forty learners per educator (SACMEQ, 2011). Parents of learners in South Africa blame large 
class sizes as the reason for their children not receiving individual attention and they are forced to seek extra tuition for them (Barbeau, 2009).

Reading levels of learners: The respondents were asked if the reading levels of the learners in their class were above average. Figure 5 reveals the responses.

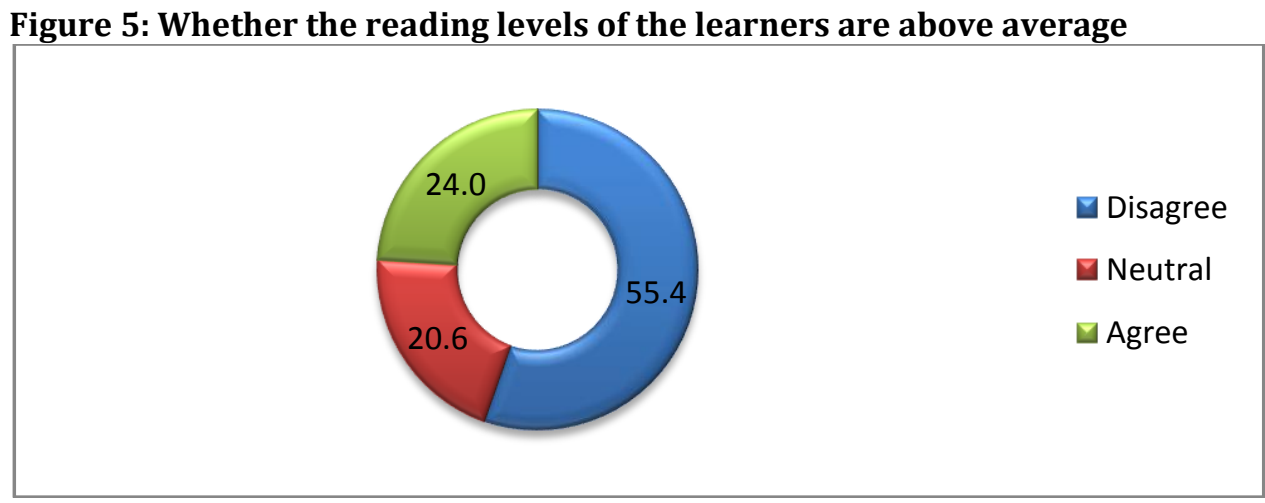

More than half (55.4\%) believed that their learners did not have above average reading abilities. About a quarter $(24.0 \%)$ of the respondents, however, indicated that their learners have above average reading abilities. $20.6 \%$ of the respondents remained neutral. According to the Centre for Evaluation and Assessment (CEA) at the University of Pretoria(2006), the results of a study conducted by the Department of Education (DoE) of South Africa in 2003 to determine the literacy levels among grade 3 learners indicated that $61 \%$ of learners cannot read and write at their appropriate age levels and that up to $18.5 \%$ learners in some provinces had to repeat grade three after being unable to satisfy the requirements of promotion to the next grade (CEA,UP, 2006). There has been no survey conducted after 2003 concerning the literacy rate of learners in primary schools, although South Africa has participated in international reading literacy assessments.

Annual National Assessment results: This section examines performance in the Annual National Assessment (ANA).

Figure 6: Whether performance of learners in the intermediate phase of the Annual National Assessment (ANA) test was poor

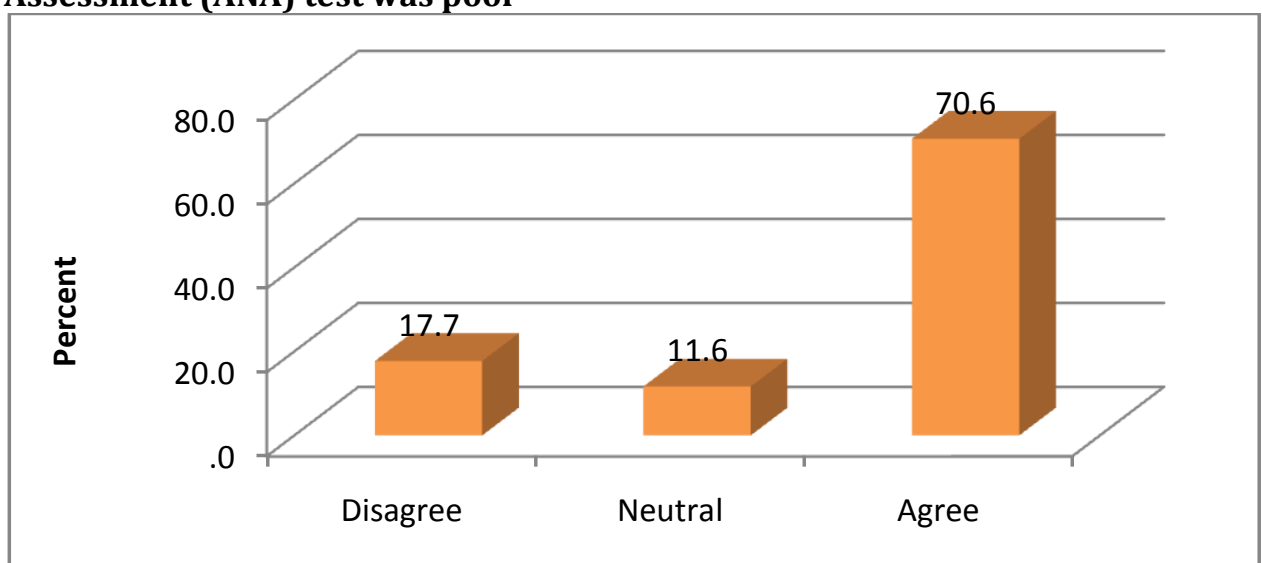

According to Figure 6, 70, 6\% of the respondents agreed that learners performed poorly in the ANA, while $17.7 \%$ disagreed. $11.6 \%$ of the respondents remained neutral. There is a noteworthy difference (52.9\%) between the respondents that agreed that the learners in the intermediate phase performed poorly in the ANA test and those that disagreed. A significant number of respondents agreed that learners performed poorly in the ANA test. According to the PIRLS 2006 scores (U.S. DoE, 2007), South Africa was rated last out of 40 participating countries. The results of the scores revealed by the respondents relate to the 2011 ANA test scores. It is also significant to note that the respondents agree that the learners' performance is still poor. Learners are to be subjected to annual national assessments in literacy, using standardized tests to measure progress regarding the achievement of set objectives (Department of Education, 2008). Despite poor performance, no remedial measures seem to be implemented. 
Time allocation for different aspects of English: This section focuses on the allocation of teaching time for the specific areas of instruction in literacy. Figure 6 illustrates the allocation of time for specific areas of instruction.

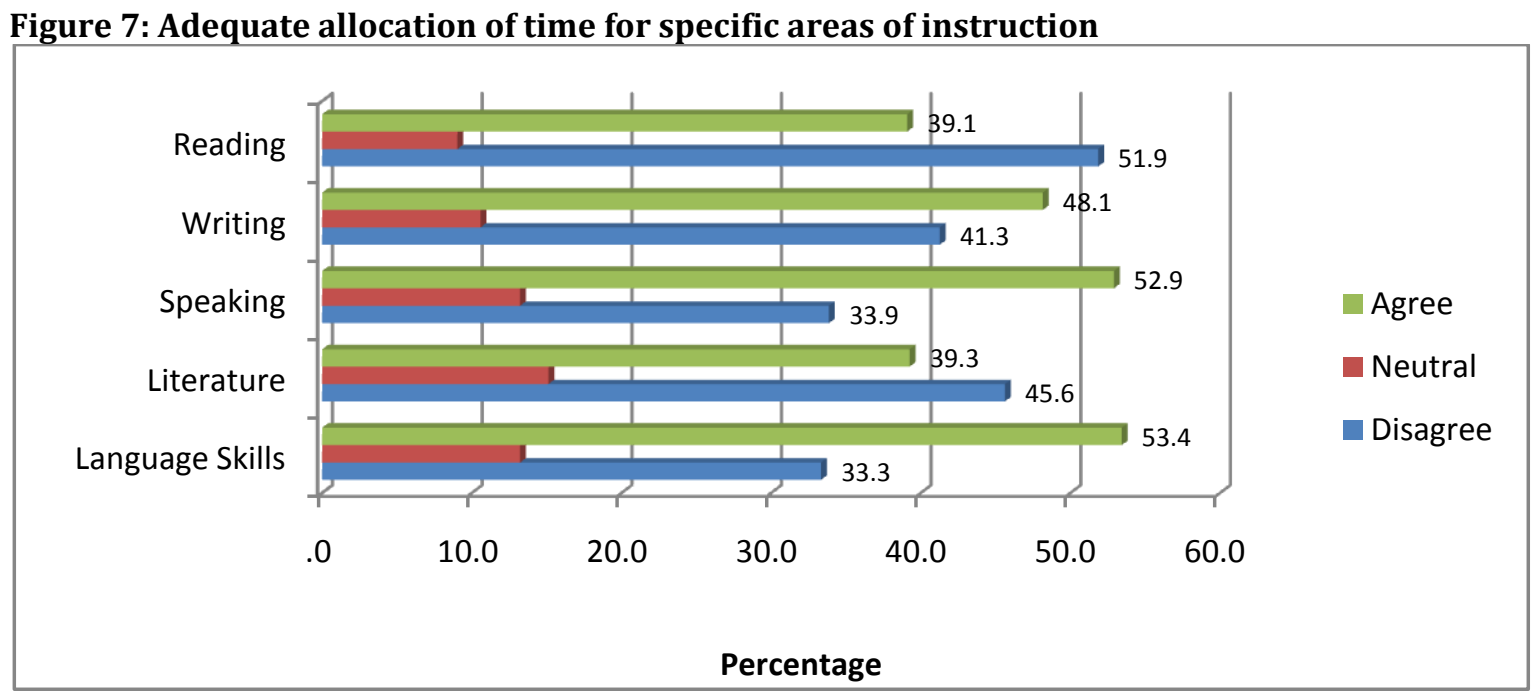

As indicated in Figure 7, 39.1\% of the respondents agreed that adequate time is given for reading instruction, while $51.9 \%$ disagreed. $48.1 \%$ of the respondents agreed that adequate time was allowed for writing activities, while $41.3 \%$ disagreed. $52.9 \%$ of the respondents agreed that adequate time was allocated for speaking as an area of instruction, while $33.9 \%$ disagreed. $39.3 \%$ of the respondents agreed that adequate time was given to literature studies, while $45.6 \%$ disagreed. $53.4 \%$ of the respondents agreed that sufficient time was allocated to the development of language skills, while $33.3 \%$ disagreed. There are much smaller differences between agreement and disagreement values. Three of the factors show slightly higher levels of agreement whilst reading and literature show greater levels of disagreement with the factors. $51.9 \%$ of the respondents stated that the time allocated for teaching of reading was inadequate. $45.6 \%$ agreed that the time allocated for literature studies is minimal. The time allocated for English is usually 5 hours in schools, which is insufficient to successfully teach the Learning Outcomes that underpin reading and writing (DoE, 2011) and this is supported by the majority response (51.9\%) that time allocated for reading is inadequate.

Reading techniques: The respondents were asked whether learners are taught reading according to specific learning styles. The results are shown in Figure 8.

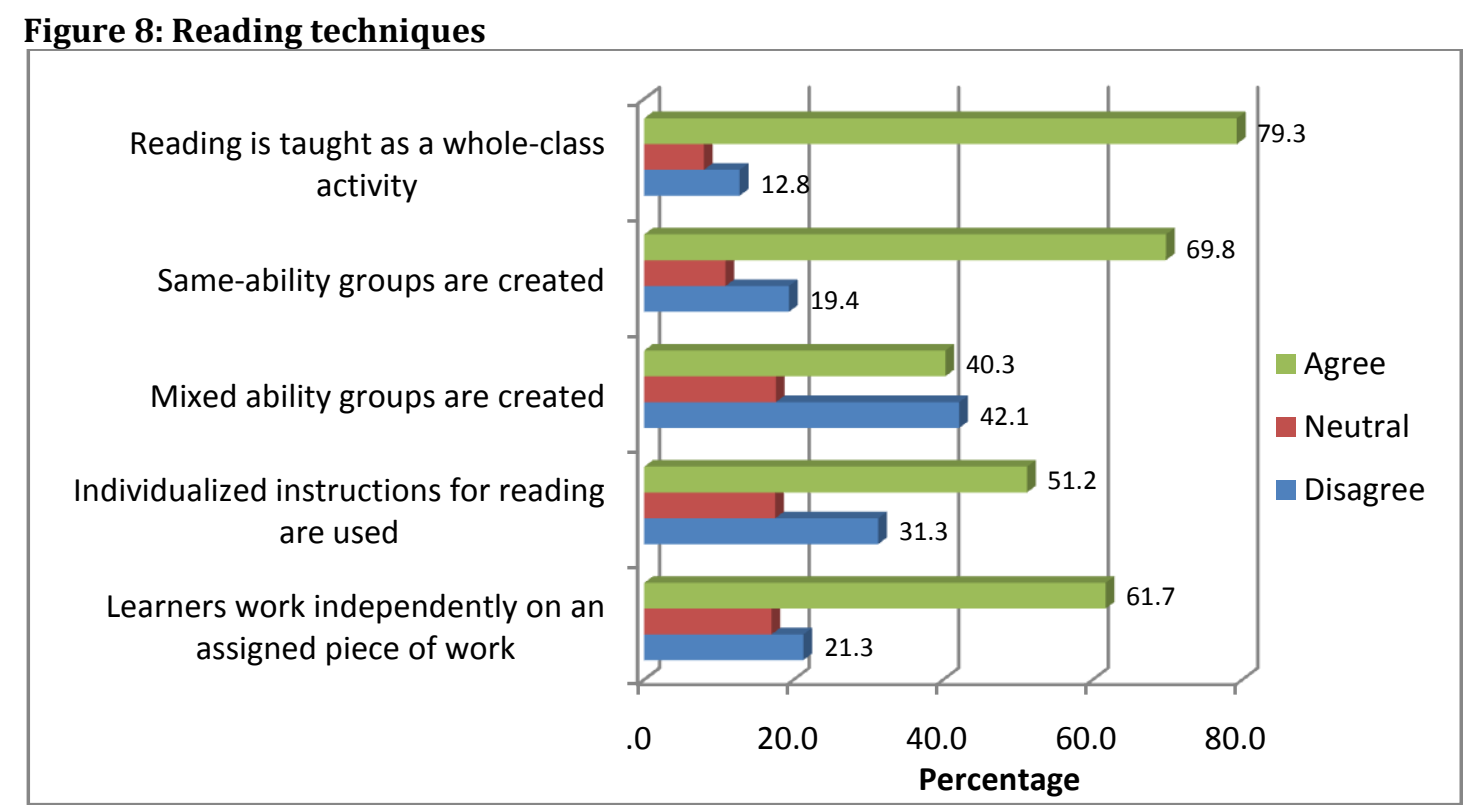


According to Figure $8,79.3 \%$ of respondents prefer teaching reading as a whole- class activity, whilst $69.8 \%$ of the respondents indicated that learners of the same abilities are grouped together for the teaching of reading. $40.3 \%$ of respondents agreed that mixed ability groups are created, while $42.1 \%$ disagreed. $51.2 \%$ of the respondents agreed that individualized instructions for reading are used while $31.3 \%$ disagreed. $61.7 \%$ of the respondents agreed that learners worked independently on assigned pieces of work, while $21.3 \%$ disagreed. There is some level of agreement for the first two statements in Figure 7 above. These reduce in value for the last two with almost an even split regarding the creation of mixed ability groups. According to the Daily News (August 13, 2009), parents of learners in South Africa blame large class sizes as the reason for their children not receiving individual attention and they are forced to seek extra tuition.

Strategies used to teach reading: This section examines the strategies used during instruction time to improve reading literacy. The results are shown in Figure 9.

\section{Figure 9: Strategies used during reading instruction time}

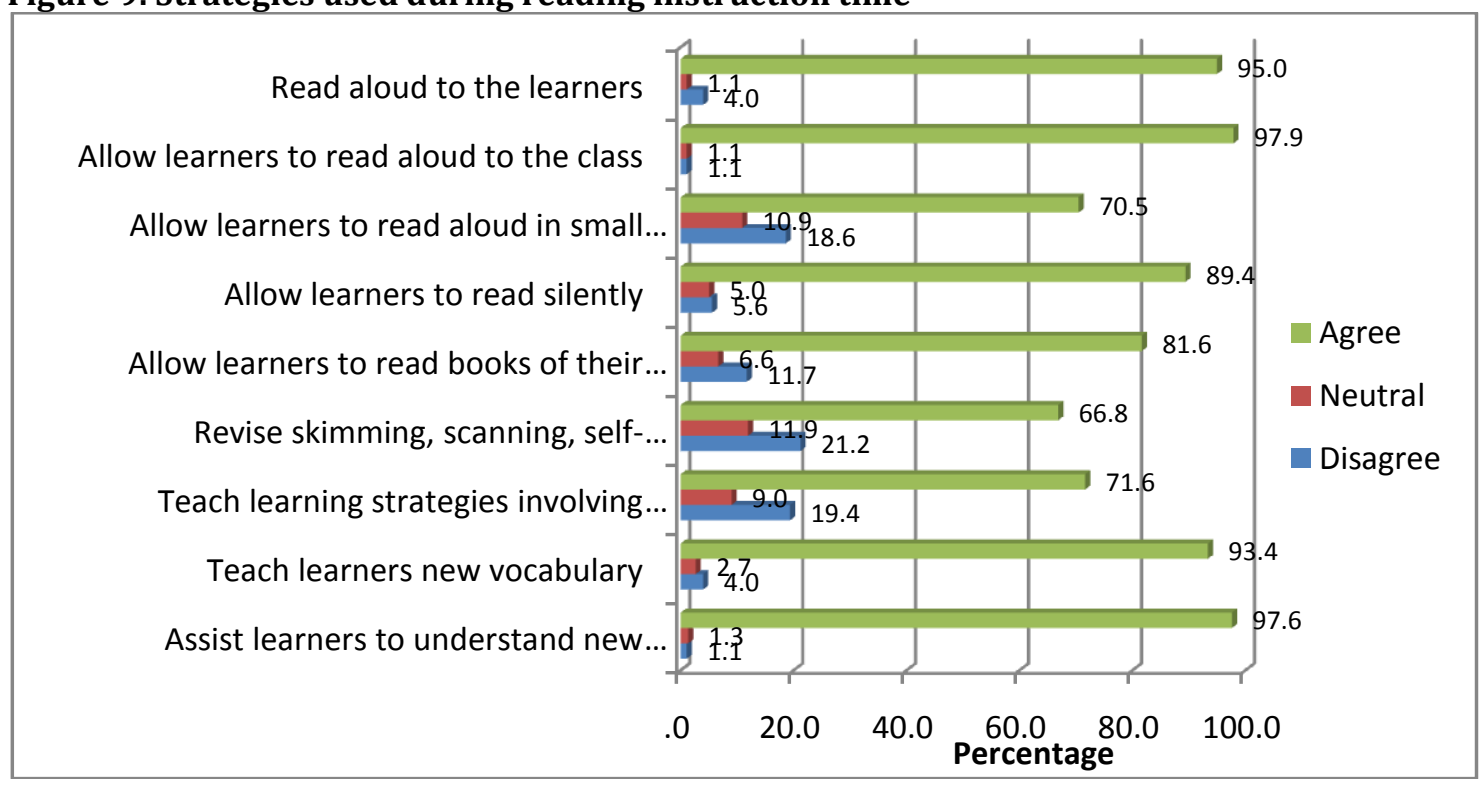

$95 \%$ of the respondents applied "read aloud" as a reading strategy and $70.5 \%$ of the respondents allowed learners to read aloud in small groups. $89.4 \%$ of the respondents allowed learners to read silently. $81.6 \%$ of the respondents agreed that they allowed learners to read books of their own choice as a reading strategy. $66.8 \%$ of the respondents applied skimming, scanning and self-monitoring methods, while $21.2 \%$ disagreed.71.6\% of the respondents taught learning strategies involving decoding sounds and words while $19.4 \%$ disagreed.93.4\% of the respondents taught learner's new vocabulary during reading instruction time and $97.6 \%$ agreed that they assisted learners with learning new vocabulary from the text they were reading. The overall pattern is one of agreement with the statements. There is very strong agreement for four statements (first two and last two), strong agreement for statements 4 and 5, and agreement levels between $66 \%$ and $72 \%$ for the remaining three statements. It is interesting to note that $95 \%$ of educators are involved in reading aloud and that $97.9 \%$ of learners are allowed to read aloud. The strategies used in the teaching of reading are applied by most educators. According to the FFL (DoE, 2009), "read aloud", "shared reading" and "guided reading" by the educator and learner, form the components of a reading programme. "Guided reading" constitutes a significant segment of the reading process.

Resources for learners with reading difficulty: As shown in Figure 10, the various reading resources available to assist learners with reading difficulties are discussed in this section. 
Figure 10: Resources available to assist learners who have reading difficulties

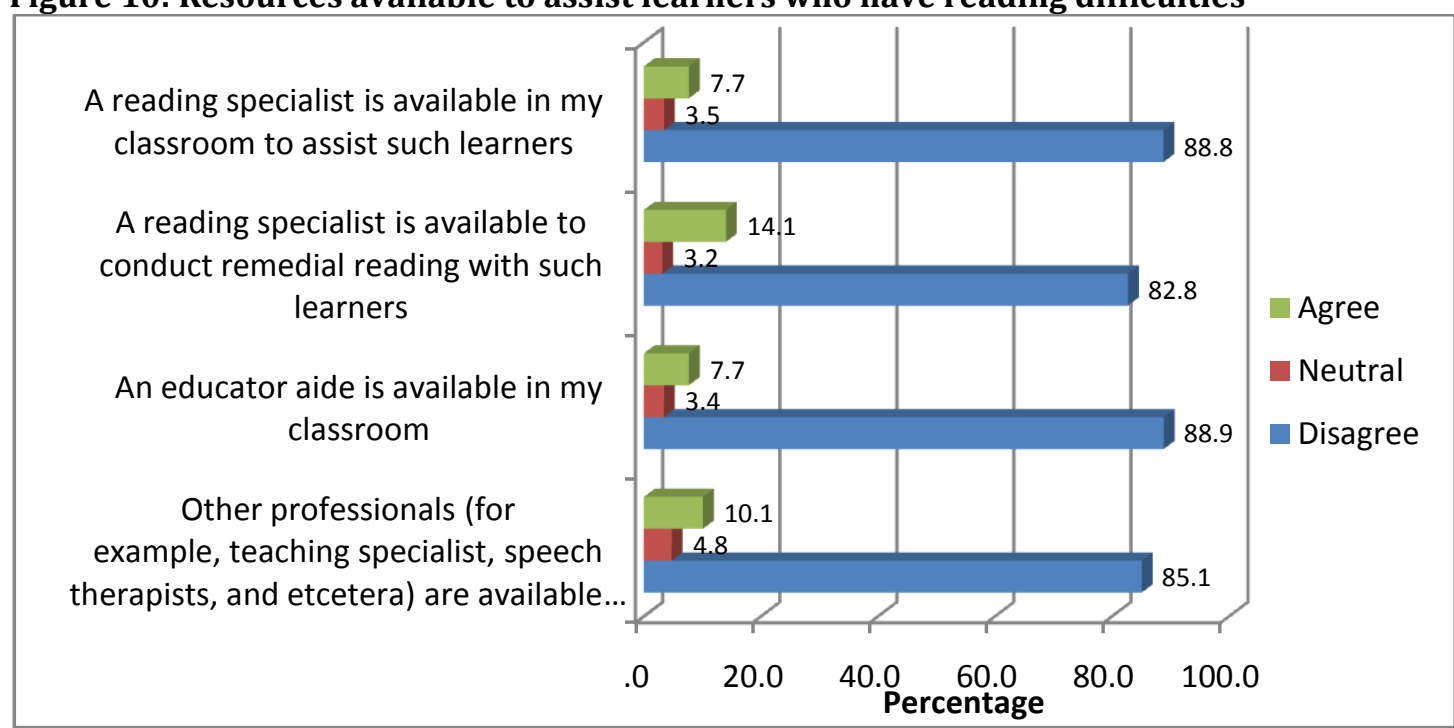

$88.8 \%$ of the respondents disagreed that a reading specialist was available to assist learners with reading difficult. $82.8 \%$ of the respondents disagreed that a reading specialist is available to conduct remedial reading with such learners. $88.9 \%$ of the respondents disagreed that an educator aide is available in the classroom to assist learners with reading difficulties and $85.1 \%$ disagreed that other professionals were available to assist learners with difficulty with reading. There are strong levels of disagreement with each of the statements in the figure above relating to the availability of resources. On average, $86.4 \%$ of respondents indicated that there are no specialist personnel or resources available for learners with reading difficulties. However, reading can be enhanced using other strategies, for example, word drills, phonics drills, sentence constructions, reading aloud, etcetera. especially in the absence of remedial educators or other resources. Educators are presumed to have adequate resources to warrant the effective teaching of reading and writing. This includes wall charts, writing materials, reading series, workbooks and writing materials (DoE, 2008).

\section{Conclusion drawn from the review of related literature}

According to the findings from the empirical study, there were a significant number of educators that received no training in teaching reading and a majority of the respondents indicated that they did not regularly attend workshops in teaching reading. According to Rose (2006), most educators have received no previous training in teaching reading. There is a need for more support from learning areas advisors in the interpretation and implementation of the curriculum. The findings further confirmed that large class sizes were indications of poor reading ability. Parents of learners in South Africa blame large class sizes as the reason for their children not receiving individual attention and they are forced to seek extra tuition for them (Daily News, 13 August, 2009); Educators in other countries, for example, England, New Zealand and the Netherlands indicated that support educators were available all the time to assist with learners with reading difficulty. In South Africa, educators do not have the assistance of support educators as learners with special needs are incorporated into the mainstream. This is termed 'inclusive education'. Specialist educators should be consulted or employed to assist with learners with reading difficulties. These educators have the knowledge and experience to deal with learners with reading complications. Reading specialists were not available to assist learners with reading difficulty or learners that required remedial reading teaching. On average, there were no specialist personnel or resources available for learners with reading difficulties. South Africa learners with special needs and severe reading problems are engaged with the help of specialists' educators who work with learners away from the usual classroom. This support for at-risk learners should be conducted in a structured programme. This facility will enable educators to measure improvement in learners and reflect on their current practices with a view of improving all learners' reading abilities. The respondents in the survey indicated that a majority of the learners required corrective teaching in reading and that learners are unable to receive corrective teaching in reading. This was due owing to time constraints and the lack of assistance of support educators. It is also recommended that extra time be allotted to the teaching of English and related aspects. For example, reading and reviewing, language, writing, listening and speaking. More educators 
need to be trained to close the gap that exists in the education system; despite the poor performance in the Annual National Assessment (ANA), no remedial measures seem to be implemented.

The majority of respondents prefer teaching reading as a whole class activity, whilst a significant number of the respondents indicated that learners of the same abilities are grouped together for the teaching of reading. Many respondents agreed that mixed ability groups are also created. "Read aloud" as a reading strategy was very popular and a significant number of the respondents allowed learners to read aloud in small groups. Educators who indicated that they engaged in 'read aloud' represent only a small demographic area. According to research done by Condy et al., (2010), learners rarely witness educators reading. It is recommended that educators engage in 'read aloud' activities as often as possible; the majority of respondents allowed learners to read silently. Several of the respondents agreed that they allowed learners to read books of their own choice as a reading strategy. A significant number of the respondents applied skimming, scanning and self-monitoring methods, while the majority of the respondents taught learning strategies involving decoding sounds and words. Most of the respondents taught learners new vocabulary during reading instruction time and it was unanimously agreed that educators assisted learners with learning new vocabulary from the text they were reading. The respondents agreed that the method of scaffolding is important, but it is not being applied during reading. The majority of the respondents to the questionnaire indicated that most of their learners were second language learners. Therefore, school libraries need to be reinstated in areas where they have collapsed. Emanating from the empirical findings, the following typology was derived to support enhanced reading literacy in the intermediate phase.

There is a dire need in South Africa for the nation's learners to experience success. There is apathy in some schools to reach the most challenged learners and this, coupled with the frustration over the slow pace of change, creates a sense of urgency. Hence, it is inevitable for researchers and organizations to intervene in various ways to overcome obstacles to academic success. There is a need for schools to strengthen the reading programmes to suit the reading levels of learners. In the absence of reading workshops, it is imperative that educators empower themselves through networking with 'sound reading' schools as mentors to improve reading performance. It is vitally important for schools to engage learners in books of various reading levels as these resources should be made available in 'operating' libraries. A close connection with the local library is fundamental to reading improvement. One such response from education is the 'turnaround' model. Evidently, it is a dramatic operation to close a school; to release most of the educators and recruit other educators; to resign the school to an external organization hopeful of improved results; to offer financial incentives for elevating the test results; or bring in innovative leadership charged with producing the desired results. For learners experiencing difficulty with poverty and structural racism, there are no immediate solutions. However, while sophisticated solutions may generate a sense of relief that action is under way, they have not fashioned turnarounds that are effective in the long-term. For educators, the primary means of interacting with learners involves engaging learners in classroom activities by means of questions. A minority of learners are consistently able to achieve success and respond positively in assessment tasks. A group of learners are able to do the aforementioned, but achieve average success. There is a third group of learners who rarely respond, are unable to understand or answer questions and are more often than not unsuccessful in assessments and any task set. According to Rose (2005), this is the result of the moral order of the classroom, which identifies learners' ability to read and understand concepts, as successful, average or unsuccessful. 


\section{Figure 10: Improving Reading Quality-Accountability of all stakeholders}

\section{EDUCATORSHOME}

- Parents to play an active role in education

- Monitor homework of learners seriously

- $\quad$ Engage in adult literacy courses if necessary

- $\quad$ Liaise with educators to discuss learners' progress

- Volunteer at schools

\begin{tabular}{|l}
\hline - Develop learners who are critical thinkers \\
- Use the half-hour compulsory reading time constructively \\
- Teach aspects of language in context \\
- Merk in close collaboration with foundation phase educators \\
- Use visual aids \\
- Use DVD's and CD's \\
- Engage learners in meaningful homework exercises \\
- Develop learners comprehension ability \\
\hline
\end{tabular}

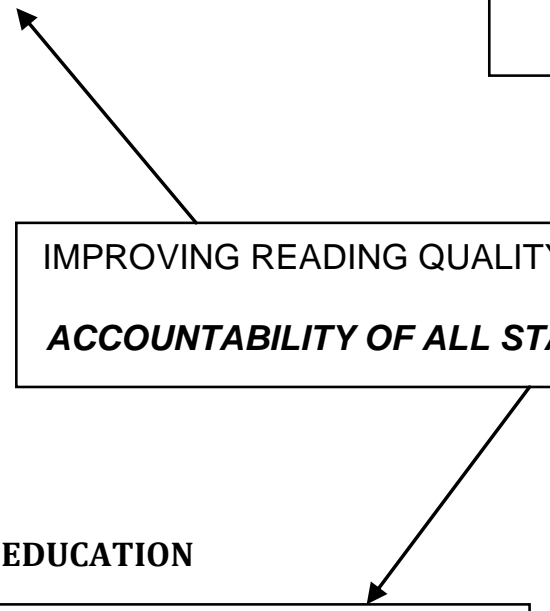

- Training of more educators

- Re-open colleges of education

- Provide incentives for education

- Re-instate collapsed libraries

- Workshop educators on instruments used for learners progress

- Re-examine administration work load of educators

- Re-examine learning outcomes and assessment standards due to time constraints

- Introduce guidance counsellors

- Introduce remedial educators

- Allot extra time for literacy learning

- More support to schools for curriculum implementation
SCHOQL MANAGEMENT TEAMS (SMT)

- Learners to be taught if possible at entry level in mother tongue

- Reading resources in isizulu to be available

- Diagnose reading problems of learners

- $\quad$ Liaise with DoE to find solutions to reading problems

- Use retired educators for remedial teaching

- $\quad$ Elicit assistance of corporate world for sponsorships of library book, computers, etc.

- Monitor educators regularly

Conclusion: Learners accept this moral order and mould their future experiences around this, creating a small profession elite group and a larger group of unskilled manual workers. As a result of the failure of educational outcomes to keep in line with social and economic changes in South Africa, the focus has been directed to literacy in schools. It is therefore important to teach learners reading skills explicitly at any stage of the curriculum instead of leaving learners to acquire these skills tacitly. Skilled readers recognise words by visually processing letter patterns, while learners with reading difficulty frequently struggle to sound out words letter-by-letter. Experienced readers read with meaning whereas learners with reading difficulty cannot read with comprehension. Therefore, in order for all learners to be able to be react to the environment they live in, reading and understanding what is read is vital to their progress in life in general.

Further Research: Areas for further research include the reviewing of the time allocated for reading in the intermediate phase. There is a need to undertake a study on a larger sample of schools. Observation of educators and school management teams in 'action' will enhance the research. Conduct research among high-performing schools in low-income/poor social backgrounds to provide solutions for schools that perform poorly. Conduct research relating to effective practices in other countries where schools are experiencing similar reading difficulties. Review the curriculum at Teacher Training Universities to ascertain reasons for the exclusion of teaching reading methods to enhance reading quality specifically in 
the intermediate phase of schooling. Motivate the need for educators in Teacher Training Universities to be taught phonic and other reading skills to use during reading in the intermediate phase. In conclusion, it is vital to reiterate that the most important constituent of high quality education is literacy. Without the ability to read, people are denied access to significant information that affect on their lives. Illiteracy in South Africa is an entrenched social phenomenon and is intimidating the transformation and development of our country. It is the duty of every literate adult to encourage and motivate learners to read so that the value of reading can be appreciated and more people can become lifelong readers.

\section{References}

Alliance for Excellent Education (2006). Issue Brief. http://www.all4ed.org/ Centre for Evaluation and Assessment (CEA). 2006. University of Pretoria (UP).

Barbeau, N. (2009). The Daily News, August 13.

Condy, J., Chigona, A., Chetty, R. \& Thornhill, C. (2010). Final year teacher training students' perception of THRASS. South African Journal of Education, 30, 261-275.

Department of Education. (2002). Revised National Curriculum Statement (RNCS) Policy.

Department of Education (2007). National Policy Framework for Teacher Education and Development (NPFTED).

Department of Education (2008). National Reading Strategy. 1-20.

Department of Education. South Africa. (2008). Foundations for Learning Campaign. (Notice 306 of 2008 ). Government Gazette No. 30880: 14 March.

Department of Eduction (2009). Quality Teaching and Learning Campaign.

Department of Education (2010). Report on the Annual National Assessments 2011. 1-36. Available at https://www.government education.com.

Department of Education (2011). A Teacher's Handbook, 2008. Teaching Reading in the Early Grades: A Teacher's Manual. Available at http://www.education.gov.za

EFA Global Monitoring Report. (2005). United Nations Educational, Scientific and Cultural Organization (UNESCO).

Howie, S. J., Venter, E. \& Van-Staden, S. (2008). The effect of multilingual policies on performance and progression in reading literacy in South African primary schools - Reading Achievement: International Perspectives from IEA's Progress in International Reading Literacy Studies (PIRLS). Education Research and Evaluation, 4(6), 551-560.

Meier, C. (2011). The foundations for learning campaign: helping hand or hurdle? South African Journal of Education, 31(4), 1-15

Mkhwanazi, S. (2008). Pandor confirms to reopen colleges. April, 25. Available at http://www.iol.co.za/news/south-africa/pandor-confirms-plans-to-reopen-colleges-1.39796 7

Moore, J. M. \& Hart, M. (2007). Access to literacy: Scaffolded reading strategies in the South African context. Journal for Language Teaching, 41(1), 15-28.

Pretorius, E. J. (2005). What do students do when they learn to read? Lessons from five case studies. South African Journal of Higher Education, 19(4), 790- 812.

Progress in International Reading Literacy Study (PIRLS). (2006). Performance at the PIRLS 2006 International Benchmarks IEA. IEA.

Rose, D. (2005). Democratising the classroom: literacy pedagogy for the new generation. Journal of Education, 37, 131-167.

Rose, D. (2006a). Learning to read: Reading to learn. Scaffolding the English curriculum for indigenous secondary students.

Rose, D. (2006b). Literacy and equality in the classroom. Future Directions in Literacy Conference. University of Sydney.

Southern and East Africa Consortium for Monitoring Education Quality (SACMEQ). (2011). Report on the Quality of Education.

U.S. Department of Education. National Centre for Education Statistics. (2007). International Association for the Evaluation of Educational Achievement Student questionnaire - PIRLS. 